\title{
Thoracic outlet syndrome: a congenital case manifesting in middle age
}

\author{
Nour Khatib MBA, Jacinthe Boulet BSc \\ See also practice article, www.cmaj.ca/lookup/doi/10.1503/cmaj.140400
}

Competing interests:

None declared.

This article has been peer reviewed.

The authors have obtained patient consent.

Affiliation: Department of Undergraduate Medical

Education, McGill

University, Montréal, Que.

Correspondence to:

Nour Khatib,

nour.khatib@mail.mcgill.ca

The authors would like to thank Drs. Ken Flegel and Lawrence Stein for their guidance and effort. Their dedication to teaching and contagious passion for medicine have helped make our publication possible.

CMAJ 2015. DOI:10.1503 /cmaj.140552
A 58-year-old man with an unremarkable medical history presented to the emergency department after one month of numbness, weakness and migrating pain in the right upper extremity. The patient is left-handed, works in an office and is an avid marathon cyclist (6-18 h/wk of exercise). On examination, pallor of the right hand was noted, but there were no signs of cyanosis. Capillary refill was slower, and blood pressure, radial and brachial pulses, and oxygen saturation were undetectable in the right upper extremity. Computed tomography (CT) angiography of the right upper extremity (Figure 1, Appendix 1 available at www.cmaj.ca/lookup /suppl/doi:10.1503/cmaj.140552/-/DC1) confirmed the presence of a cervical rib posterior to the subclavian artery and a large poststenotic dilatation. In addition, there was an aneurysm in the subclavian artery and evidence of diffuse thromboembolic disease involving the axillary, brachial, ulnar and radial arteries. The patient underwent subclavian artery to axillary artery bypass with saphenous vein graft to repair the aneurysm in the

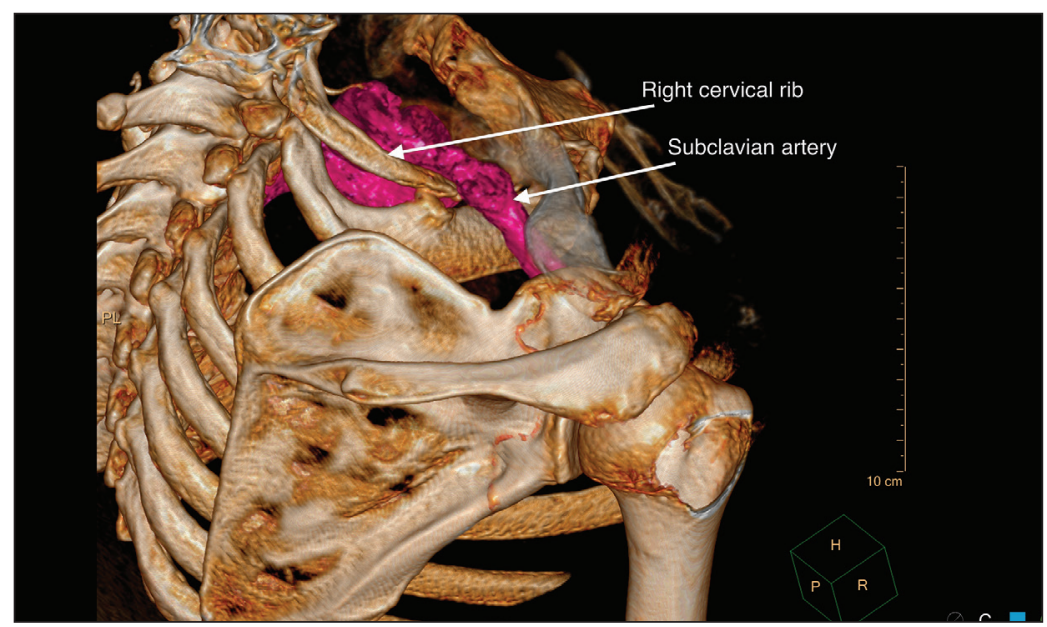

Figure 1: Three-dimensional reconstruction of a computed tomography angiography of the chest and right upper extremity in a 58-year-old man showing a right cervical rib articulating with the anterior aspect of the right first rib. There is a nonobstructive thrombus in the distal subclavian artery. subclavian artery, resection of the right cervical rib via a supraclavicular approach and thrombectomy of the four arteries involved. Postoperatively, he is free of symptoms and has regained full function in his right upper extremity.

About $1 \%$ of diagnoses of thoracic outlet syndrome are attributable to vascular compromise of the subclavian or axillary artery (e.g., by a cervical rib, an anomalous first rib, muscular or vascular variants, or trauma). ${ }^{1}$ Almost all cases of arterial thoracic outlet syndrome are linked to a cervical or other anomalous rib formation and are associated with arterial thromboembolism. ${ }^{1}$ In these cases, ischemia in the upper extremity occurs, with pallor, pain, paresthesias and changes in distal pulses, as well as decreased systolic blood pressure and auscultatory bruits. ${ }^{1}$ Diagnostic procedures to identify arterial thoracic outlet syndrome include ankle-brachial index, measurement of segmental pressures in the upper limb and imaging studies to assess the presence of a rib anomaly (e.g., chest radiograph, CT scan) or possible arterial occlusion (duplex ultrasonography or CT angiography). ${ }^{1}$ The differential diagnosis includes artery atherosclerosis in the upper limb, Raynaud phenomenon, vasculitis, vasospastic disorder, carpal tunnel syndrome and acute coronary syndrome. ${ }^{1}$ Treatment of symptomatic patients typically necessitates surgical removal of the abnormal structure, repair or resection of the involved artery if necessary, vascular bypass and distal embolectomy. ${ }^{1}$

\section{Reference}

1. Daniels B, Michaud L, Sease F Jr, et al. Arterial thoracic outlet syndrome. Curr Sports Med Rep 2014;13:75-80.

Clinical images are chosen because they are particularly intriguing, classic or dramatic. Submissions of clear, appropriately labelled highresolution images must be accompanied by a figure caption and the patient's written consent for publication. A brief explanation (250 words maximum) of the educational significance of the images with minimal references is required. 